\title{
Students conceptions about the impact of monolingualism on learning with heterogeneous classes in an PE session: Case of the French primary school Robert Desnos in Tunisia
}

\author{
Fraj Houssem Eddine ${ }^{1}$, Bali Naila ${ }^{2,3}$ \\ ${ }^{I}$ (High Institute of Sport and Physical Education, Ksar Saîd, University la Manouba, Tunis,Tunisia) \\ ${ }^{2}$ (High Institute of Sport and Physical Education, Ksar Saîd, University la Manouba, Tunis,Tunisia) \\ 3(Tunisian Research Laboratory: «Sport Performance Optimization», Tunis, Tunisia.)
}

\begin{abstract}
Inscribed in the field of language didactics, Physical and Sports activities didactics, this study is based on a survey of students' conceptions about the impact of monolinguals' on learning with heterogeneous classes during a PE session at the French primary school Robert Desnos in Tunisia. In this research, we underway from a concretely observed phenomenon in the French schools abroad and from a central question posed by this manifestation. We took the example of one of these schools located in Tunisia. By the observable phenomenon we indicate the progressive emergence of the heterogeneity's concept in the teachers' current language which returns mainly to the different mutations of the French educational system.
\end{abstract}

The purpose of This paper was to study students' conceptions about the impact of language interactions during the PE session at the French school in Tunisia and to examine their impact on the learning of students issued from diverse nationalities, and speaking different native languages.

The used method consists on an interrogatory with one of the two actors of the teaching-learning situation: "the teachers" $(N=171)$. Data were collected through a questionnaire that we elaborated based on the age (9 to 11 years), the language commonly mastered by the students (language school) and their assimilation degree determined by their ethnicity (nationality) and school (some of them were registered in the third year of primary school "CE2", others come from mutations, while those of the third category were not registered in French schools).

The empirical results of the study show that the linguistic interactions of the didactic situation in PE in the French school in Tunisia are mainly monolingual in French despite the ethnic diversity and the linguistic heterogeneity of the school audience. This French discourse appears relatively effective such as it does not allow the transmission of the instructions to all students either because they are not basically francophone and they do not practise the French language in their familial environments, or because they have not joined the French school since the nursery school which plays, in the French schools abroad, the role of a mediator between the school learning environment and the familial learning environment.

The presence of students not mastering sufficiently the French language in a PE classroom requires, in our opinion, other things instead of technical adjustments (schematization, demonstration, groups levels ... etc). It requires a reflection and an adaptation, especially linguistics, while programming the specific teaching contents of the French schools abroad. This adjustment is indispensable as long as "the Official programs are established for all primary schools in France. They are intended for all, but in reality, they do not seem appropriate to any of them in particular. Want to apply them uniformly everywhere is an unrealizable" (Charrier, 1918).

We assist therefore on a certain inadequacy between the French monolingual educational approach and the specificities of the linguistically heterogeneous school public in the Tunisian context. This lack of correspondence (mismatch) may therefore increase more the phenomenon of "unequal opportunities" between students already francophone and those who do not master the French language sufficiently.

Keywords: Physical Education - Conceptions - Monolinguals' - Heterogeneity - Learning. 


\section{Introduction}

At the beginning of our study of this research's subject we mention that "Creating more equitable societies has been an important mandate of mass education for some time and is reflected in equity policy across the globe. A key concern within western policy discourse relates to raising the schooling participation and achievement of marginalized groups" (Keddie. A \& al, 2012, p.91)

Inscribed in a wide field of research which link the linguistic, the perceptional activities and action in the physical world, this study aims to better understand the PE learning and the French language learning by addressing the dialogue student-teacher under the PE session into a dynamic interaction at the French school in Tunisia.

Considered as a discipline of verbal and nonverbal interactions between the two poles of the teachinglearning situation, the PE allows to the student to acquire a set of knowledges and expertises about the physical exercise and the knowledge of its effects, the self-knowledge, and the possibility to act on its own potential to develop or maintain his skills and abilities. Thus, "To melt into the mold of the French educative system, it has, along the way, the same institutional characteristics as the other disciplines: formal programs, certified evaluation of motor behavior incurred by the students and an pedagogical and didactic implementation submitted to explicit educational standards "(Dugas, 2004, p. 21).

Moreover, the semio-constructivist approach in physical and sports education is a new and innovative approach of research in didactics of physical and sports activities. Recent studies carried out in this framework have carried on the main role of linguistic interaction in the co-construction of knowledge (Gréhaigne \& al., 2001; Mahut, 2003; Nachon, 2004; Chang, 2009). These latter have emphasized the importance of verbalization in the teaching-learning process. Also, the approach of Vygotsky and the neo-Vygotskian seems to be the reference theory in the scholar learning. It consists on a thought functioning conception where the language and the social factors play an important role in the knowledge construction process (Coll, 2002). In this same perspective, Mahut and Gréhaigne (2000) postulate that the learning process can be perceived as a situation of total communication in which the learner receives a message and acts in accordance with it. Thus, the language is at the heart of learning.

In this research, we underway from a concretely observed fact in the French schools abroad and from a central question posed by this manifestation. We took the example of one of these schools established in Tunisia. By the observable fact we indicate the progressive emergence of the concept of heterogeneity in the teachers' current language which returns mainly to the different mutations of the French educational system.

Thus, according to Suchaut (2007), the concept of heterogeneity has emerged gradually in the teachers' common parlance further to the evolution of the French educational system. This evolution has been concretized on the ground by mutations in the public school composition. And the students' diversity is basically the product of two mechanisms: The first is the increase of the schoolchildren number (mass education phenomenon) that allowed to an entire age class to access to school curriculums more and longer. The second mechanism is the abolition of some orientation bearings, of sectors, but also a slight decrease of repetition. Indeed is added a social, economic and cultural upheaval that was at the origin of changes in the relationship of individuals to school, this is reflected by a less receptive student's audience to the traditional school standard. For these reasons, from the nursery school to university, the students population has become more diverse, leading to greater difficulty in the exercise of the teachers' work. Often privileged in the actors' discourse, this heterogeneity covers several dimensions among the students: the level of acquisition, cognitive capacities, linguistic diversity, scholar behavior, social environment ...etc.

Tarin (2006) postulated that the concept of school heterogeneity refers naturally to inequality, but also to diversity and difference. Inequality vis-à-vis the culture and knowledge first. We talk so willingly "level" of dissimilarity apprehended in terms of expected skills (linguistic skills, ability to argue, to conceptualize, logical reasoning etc...) but also of mastering a number of an indispensable knowledges.

Similarly, in his report to the National Educational Minister, Bouchez (1994) writes that the public school heterogeneity at the French school seems to be divided following two criteria; students from very different school level in the basic knowledges and especially in the ability to master the language and those whose behavior poses integration problems in the classroom or the school.

Furthermore, for Tarin (2006) the cultural diversity is often one manifestation of the students' heterogeneity in school. Furthermore, the juxtaposition of different nationalities within the school community 
regularly causes a number of problems. Communication problems related mainly to the insufficient master of the French language. However, beyond the handling of a linguistic system intended for exchanging meanings, the language as a communicational tool is also a way of criticism of the human experience and specific analysis for each cultural community. It should be mentioned, that in situations of intercultural communication, the communication language (French in our case) can also be a source of misunderstanding or misinterpretation of unexpected behavior, clearly expressing a sense of interference and social codes. Our author argues that, in a multicultural environment the origin of an understanding and communicating difficulty is frequently rooted into the cultural specificity itself. This latter refers to a number of "social objects "generating representations that affect identity. It is there the moment of attitudes and connotations interpretations, that of the axiological dimensional expression of culture. It is, according to him, an essential dimension of communicative competence, a concept that tends to become a capital theme of reflection on language didactics.

Also, to clarify the relationship between students' heterogeneity and academic learnings Galand (2009) refers to the views of many teaching experts in our country. According to him the answer is fairly obvious: the more heterogeneity is significant within the same class, the more their work become difficult and less these professionals can effectively support their students' learning. He adds that if we agree with this opinion, reducing the heterogeneity of a group of learners will certainly allow a better teaching adjustment on the level of students' knowledge and raise, therefore, a learning gain.

Besides, according to Bali and al (2013), throughout the last few decades, the management of the schoolchildren heterogeneity has always been a complex process in French schools abroad, where students are different by their behaviour, their interests, their previous knowledge,, their rate of abstraction, their expression capacities, their pedagogical and especially their ethnic and social origin profile.

Deals with this multidimensional heterogeneity phenomenon, the teachers are therefore demanded to provide heterogeneous responses to allow some students to improve themselves without wasting time and to help those in need to fill their gaps.

We therefore agree that the school public heterogeneity will underpin one or more native languages reflecting the cultural diversity, the juxtaposition of multiple nationalities in the resulting school community will certainly pose a number of problems. Communication problems mainly related to the insufficient mastery of the French language in front of a predominantly monolingual speech.

One therefore wonders about the impact of the monolingual speech characterize the teacher-student interactions on the teaching content at the French primary schools in the Tunisia, and on the ability of the student to assimilate this content.

Thus, does the French monolinguals' allow a better access to knowledge with heterogeneous classes?

Otherwise, does a teaching approach based on the French language, with students issued from different nationalities, promote effectively the act of learning on PE or it inhibits it?

\section{Method}

In this study we are dealing with a purely descriptive approach which seeks to study the verbal exchange of the teaching-learning situations at the French schools abroad in Tunisia. The research protocol proposed in this study consists on a census of the students' conceptions about the language interactions during the PE session. It aims also to examine the impact of these interactions on the learning process in the discipline mentioned above with pupils notable by the diversity of their nationalities and therefore their native languages.

To study the linguistic nature of the verbal interactions in the PE session at the French school in Tunisia, especially in Robert Desnos school. And secondly, to identify the impact of these exchanges, predominantly monolingual, on PE learning with an audience characterized by its multiple nationalities and its native languages ... We proceeded through questionnaires that we created according to the surveyed students' specificities: their diversity or heterogeneity, their degree of assimilation, commonly mastered language (school language)...etc.

In order to maximize the possibilities to cover the linguistic usages during the PE session at the French school in Tunisia, we interrogated all students registered in the fourth year of primary school "CM 1" at Robert Desnos school during the school year 2011/2012. 
We mention that the surveyed students' are all between nine (09) and ten (10) years old, they are issued from diverse nationalities and are talking different native languages. Our sample is composed from seventy nine (79) girls and ninety two (92) boys subdivided into seven (07) classes.

We chose this level because it is part of the consolidation cycle "cycle3" in which it operates the culmination of the previous cycles learnings "Cycle1 and Cycle2".

We note that the surveyed students' are all between nine (09) and ten (10) years old, they are issued from diverse nationalities and are talking different native languages. Our sample is composed from seventy nine (79) girls and ninety two (92) boys subdivided into seven (07) classes.

The questionnaire is composed of nine (09) questions related to the linguistics usages in the PE session at the French schools abroad, their effectiveness and the language mainly preferred for PE learning at the in the north African context generally, and the Tunisian context in particular. These questions ranged from "closed questions" (Yes or No questions) to "pre-coded", also known as multiple choice questions, offering a series of answers from which the student chooses one that meets or best reflects his opinion. We have presented these questions in a logical sequence.

The administration of the questionnaire was conducted during the school year third quarter, just after the Rugby cycle insured in collaboration between the class teacher and a bilingual intervenor. The administration took place in the classrooms after taking appointments with the surveyed students' teachers. We proceeded to a detailed explanation of each question to ensure its understanding and to avoid the arbitrary answers. Similarly, we have answered all the questions they asked to help them answering correctly.

The survey counting allowed us to identify the statistical tool "chi2" used to analyze the differences between student's responses and interpret them.

We present below our sample work summarized in the following table.

Table 1

Fourth year of primary school students' sample of the French school Robert Desnos in Tunisia

\begin{tabular}{ccccccccc}
\hline & & CM 1 & CM 1 & CM 1 & CM 1 & CM 1 & CM 1 & CM 1 \\
Nationalities & & A & B & C & D & E & F & G \\
\hline \multirow{5}{*}{ Age } & French & 0 & 0 & 0 & 1 & 4 & 0 & 1 \\
& Tunisian & 6 & 4 & 8 & 6 & 8 & 6 & 8 \\
& Franco-Tunisian & 10 & 17 & 10 & 9 & 10 & 12 & 12 \\
Origins & Other & 8 & 3 & 8 & 8 & 2 & 7 & 3 \\
& 9 years & 1 & 1 & 1 & 1 & 1 & 0 & 0 \\
& 10 years & 22 & 23 & 24 & 22 & 19 & 24 & 24 \\
& 11 years & 1 & 0 & 1 & 1 & 4 & 1 & 0 \\
& $\begin{array}{c}\text { Not inscribed the } \\
\text { previous year }\end{array}$ & 4 & 2 & 0 & 5 & 2 & 3 & 2 \\
& $\begin{array}{c}\text { Third year of primary } \\
\text { school "CM 2" } \\
\text { Mutation }\end{array}$ & 22 & 22 & 24 & 19 & 22 & 22 & 22 \\
\hline
\end{tabular}

CM 1 - A : The fourth year (4th) of primary school A

CM 1 - B : The fourth year (4th) of primary school B

CM 1 - C : The fourth year (4th) of primary school C

CM 1 - D : The fourth year (4th) of primary school D

CM 1 - E : The fourth year (4th) of primary school $\mathbf{E}$

CM 1 - F : The fourth year (4th) of primary school $\mathbf{F}$

CM 1 - G : The fourth year (4th) of primary school $\mathbf{G}$

\section{Results}

The Table below shows the results collected from the "questionnaire" conducted with the students of the fourth year of primary school (CM 1) at the French school Robert Desnos in Tunisia : 
Table 2

Results of the questionnaire conducted with the fourth year of primary school students'

\begin{tabular}{|c|c|c|c|}
\hline Questions & & $\begin{array}{c}\text { Number of } \\
\text { responses per } \\
\text { category }\end{array}$ & pourcentage \\
\hline \multirow[t]{7}{*}{ Question 1 } & Fr & 6 & $3.50 \%$ \\
\hline & $\operatorname{Tn}$ & 46 & $26.90 \%$ \\
\hline & Other & 19 & $9,94 \%$ \\
\hline & $\mathrm{Fr}+\mathrm{Tn}$ & 80 & $46.78 \%$ \\
\hline & Fr + Other & 7 & $4.09 \%$ \\
\hline & Tn + Other & 8 & $4.67 \%$ \\
\hline & $\mathrm{Fr}+\mathrm{Tn}+$ Other & 7 & $4.09 \%$ \\
\hline \multirow[t]{7}{*}{ Question 2} & $\mathrm{Fr}$ & 46 & $26.90 \%$ \\
\hline & Arb & 31 & $18.12 \%$ \\
\hline & Other & 4 & $2.33 \%$ \\
\hline & $\mathrm{Fr}+\mathrm{Arb}$ & 80 & $46.78 \%$ \\
\hline & $\mathrm{Fr}+$ Other & 10 & $5.84 \%$ \\
\hline & Arb + Other & 0 & $0 \%$ \\
\hline & $\mathrm{Fr}+\mathrm{Arb}+$ Other & 1 & $0.58 \%$ \\
\hline \multirow[t]{5}{*}{ Question 3} & NS & 139 & $81.28 \%$ \\
\hline & $\mathrm{PC}$ & 22 & $12.86 \%$ \\
\hline & CE 1 & 2 & $1.16 \%$ \\
\hline & CE 2 & 8 & $4.67 \%$ \\
\hline & CM 1 & 0 & $0 \%$ \\
\hline \multirow[t]{3}{*}{ Question 4} & Fr & 152 & $88.88 \%$ \\
\hline & $\mathrm{Fr}+\mathrm{Arb}$ & 6 & $3.50 \%$ \\
\hline & $\mathrm{Fr}+$ Other & 13 & $7.60 \%$ \\
\hline \multirow[t]{2}{*}{ Question 5} & Yes & 160 & $93.56 \%$ \\
\hline & No & 11 & $6.43 \%$ \\
\hline \multirow[t]{4}{*}{ Question 6} & Fr & 149 & $87.13 \%$ \\
\hline & $\mathrm{Fr}+\mathrm{Arb}$ & 11 & $6.43 \%$ \\
\hline & $\mathrm{Fr}+$ other & 11 & $6.43 \%$ \\
\hline & $\mathrm{Fr}+\mathrm{Arb}+$ Other & 0 & $0 \%$ \\
\hline \multirow[t]{2}{*}{ Question 7} & Yes & 161 & $94.15 \%$ \\
\hline & No & 10 & $5.84 \%$ \\
\hline \multirow[t]{3}{*}{ Question 8} & Easy to Understand & 140 & $81.87 \%$ \\
\hline & Difficult to Understand & 9 & $5.26 \%$ \\
\hline & Other & 22 & $12.86 \%$ \\
\hline \multirow[t]{3}{*}{ Question 9} & Fr & 134 & $78.36 \%$ \\
\hline & Arb & 20 & $15.20 \%$ \\
\hline & Other & 11 & $6.43 \%$ \\
\hline
\end{tabular}

Fr : French

Tn : Tunisian

Other : Other nationality / Other language

$\mathbf{F r}+\mathbf{T n}:$ Franco-Tunisian

Fr + Other : French and Other nationality / French and Other language

Tn + Other : Tunisian and Other nationality

$\mathbf{F r}+\mathbf{T n}+$ Other : French, Tunisian and Other nationality

Arb : Arab

Fr + Arb : French and Arab

Arb + Other : Arab and Other language. 
Fr + Arb + Other : French, Arab and Other language

NS : Nursery School

PC : Preparatory Course (the first year of primary school)

CE 1 : The second year $\left(2^{\text {nd }}\right)$ of primary school

CE 2 : The third (3rd) year of primary school

CM 1 - A : The fourth year (4th) of primary school A

CM 1 - B : The fourth year (4th) of primary school B

CM 1 - C : The fourth year (4th) of primary school C

CM 1 - D : The fourth year (4th) of primary school D

CM 1 - E : The fourth year (4th) of primary school $\mathbf{E}$

CM $1-\mathbf{F}$ : The fourth year (4th) of primary school $\mathbf{F}$

CM 1 - G : The fourth year (4th) of primary school $\mathbf{G}$

\section{Discussion}

We present the results of the first question in table 2 .

Question1 : What is your nationality?

Table 3

Students' Nationalities

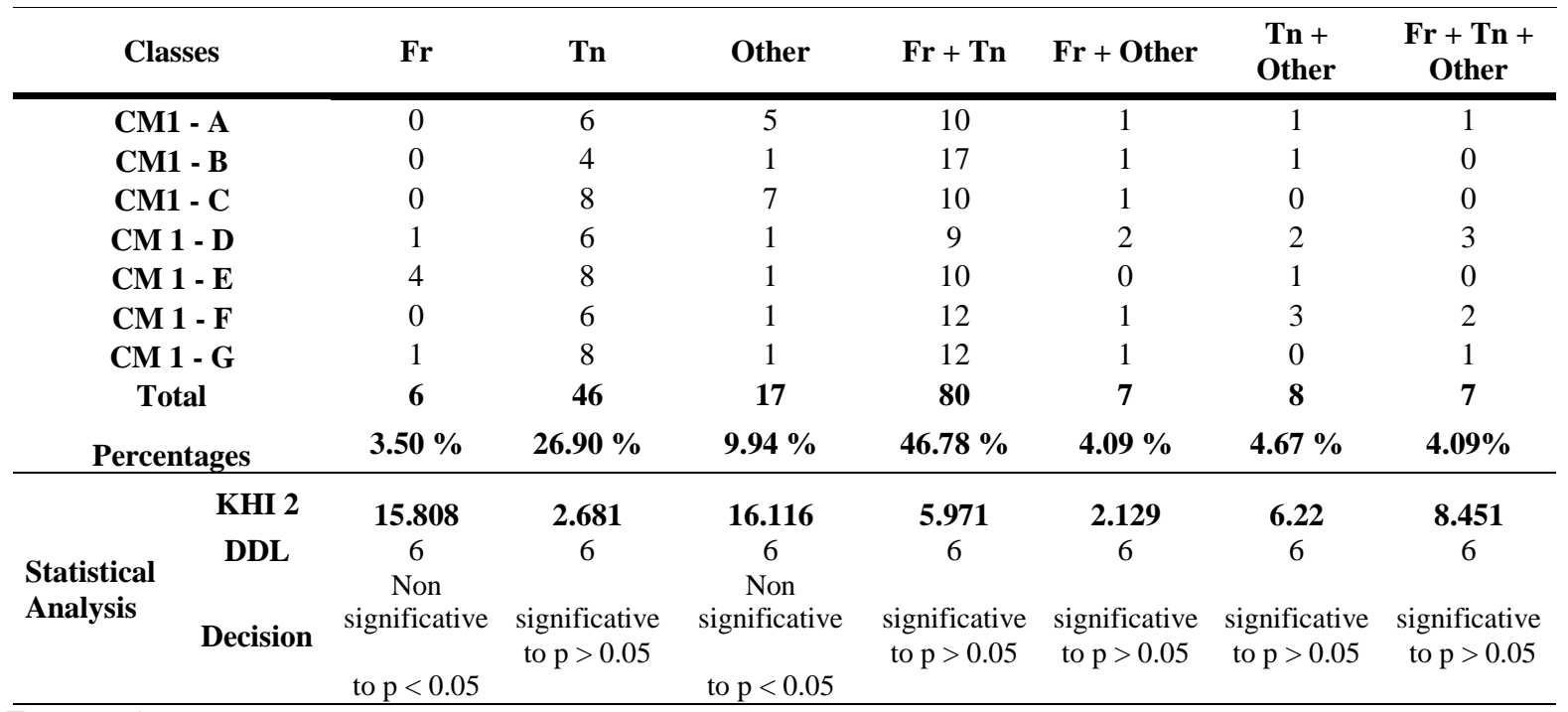

Fr : French

Tn : Tunisian

Other : Other nationality

$\mathbf{F r}+\mathbf{T n}$ : Franco-Tunisian

Fr + Other : French and Other nationality

Tn + Other : Tunisian and Other nationality

$\mathbf{F r}+\mathbf{T n}+$ Other : French, Tunisian and Other nationality

CM 1 - A : The fourth year (4th) of primary school A

CM 1 - B : The fourth year (4th) of primary school B

CM 1 - C : The fourth year (4th) of primary school C

CM 1 - D : The fourth year (4th) of primary school D

CM 1 - E : The fourth year (4th) of primary school $\mathbf{E}$

CM 1 - F : The fourth year (4th) of primary school $\mathbf{F}$

CM 1 - G : The fourth year (4th) of primary school $\mathbf{G}$

The analysis of the first question results, confirms the socio-cultural diversity of students within the same level, at the French school in Tunisia. We assist therefore to a variety of nationalities.

Indeed, this diversity will certainly underlies similarities between students of the same crop on one side and dissimilarities between those issued from different cultures, on the other hand. And it is on these latters that the educational institution is supposed to focus its work to ensure equal chances between students from the same scholar level.

That is to say that, even if the school is carrying a unique culture and is intended to all, it is still faced to students who are very close while others are very far. The least would be to consider the way to go, by 
according more imagination, time, attention, care, and work to the learners having the longest way to go. Also for those who, regardless of their distance from the school culture, learn more slowly, with more difficulty, that their source is intellectual, emotional or relational (Perrenoud, 2005).

We present in the table below the results of the second question.

Question 2: What is your native language?

Table 4

Students' native languages

\begin{tabular}{|c|c|c|c|c|c|c|c|c|}
\hline \multicolumn{2}{|c|}{ Classes } & Fr & Arb & Other & $\mathbf{F r}+\mathbf{A r b}$ & fr + Other & $\begin{array}{l}\text { Arb + } \\
\text { other }\end{array}$ & $\begin{array}{c}\text { Fr }+ \text { Arb }+ \\
\text { Other }\end{array}$ \\
\hline \multicolumn{2}{|c|}{ CM 1 - A } & 9 & 0 & 1 & 13 & 1 & 0 & 0 \\
\hline \multicolumn{2}{|c|}{ CM 1 - B } & 5 & 2 & 0 & 16 & 1 & 0 & 0 \\
\hline \multicolumn{2}{|c|}{ CM 1 - C } & 7 & 5 & 0 & 11 & 3 & 0 & 0 \\
\hline \multicolumn{2}{|c|}{ CM 1 - D } & 3 & 5 & 1 & 11 & 4 & 0 & 0 \\
\hline \multicolumn{2}{|c|}{ CM 1 - E } & 8 & 12 & 1 & 3 & 0 & 0 & 0 \\
\hline \multicolumn{2}{|c|}{ CM 1 - F } & 5 & 2 & 1 & 16 & 1 & 0 & 1 \\
\hline \multicolumn{2}{|c|}{ CM 1 - G } & 9 & 5 & 0 & 10 & 0 & 0 & 0 \\
\hline \multicolumn{2}{|c|}{ Total } & 46 & 31 & 4 & 80 & 10 & $\mathbf{0}$ & $\mathbf{1}$ \\
\hline \multicolumn{2}{|c|}{ Percentages } & $26.90 \%$ & $18.12 \%$ & $2.33 \%$ & $46.78 \%$ & $5.84 \%$ & $0 \%$ & $0.58 \%$ \\
\hline \multirow{3}{*}{$\begin{array}{l}\text { Statistical } \\
\text { Analysis }\end{array}$} & KHI 2 & 7.709 & 25.277 & 4.199 & 16.481 & 10.014 & $\begin{array}{c}\text { No } \\
\text { statistics }\end{array}$ & 5.874 \\
\hline & DDL & 6 & 6 & 6 & 6 & 6 & are & 6 \\
\hline & Decision & $\begin{array}{c}\text { significative } \\
\text { to } \\
p>0.05\end{array}$ & $\begin{array}{c}\text { Non } \\
\text { significative } \\
\text { to } \mathrm{p}<0.05\end{array}$ & $\begin{array}{c}\text { significative } \\
\text { to } \\
p>0.05\end{array}$ & $\begin{array}{c}\text { Non } \\
\text { significative } \\
\text { to } \mathrm{p}<0.05\end{array}$ & $\begin{array}{c}\text { significative } \\
\text { to } \\
p>0.05\end{array}$ & $\begin{array}{l}\text { computed } \\
\text { because } \\
\text { it is a } \\
\text { constant }\end{array}$ & $\begin{array}{c}\text { significative } \\
\text { to } \\
p>0.05\end{array}$ \\
\hline
\end{tabular}

Fr : French

Arb : Arab

Other : Other language

Fr + Arb : French and Arab

Fr + Other : French and Other language

Arb + Other : Arab and Other language.

$\mathbf{F r}+\mathbf{A r b}+$ Other : French, Arab and Other language

CM 1-A : The fourth year (4th) of primary school A

CM 1 - B : The fourth year (4th) of primary school B

CM 1- C : The fourth year (4th) of primary school C

CM 1 - D : The fourth year (4th) of primary school D

CM 1 - E : The fourth year (4th) of primary school $\mathbf{E}$

CM 1 - F : The fourth year (4th) of primary school $\mathbf{F}$

CM 1 - G : The fourth year (4th) of primary school $\mathbf{G}$

Through the data collected from the second question, we can notice that the linguistic heterogeneity of students belonging to the same level ( fourth year of primary school in our case) at the French school in Tunisia. We mention that this heterogeneity varies largely depending on these students nationalities.

The supremacy of French-Arabic bilingualism is not explained only by the high percentage of FrancoTunisian students, but also by the importance of "practical socialization" process within the familial environment and, in particular, the role that parents play to inculcate and to establish a linguistic culture among children" The experience at home is crucial in language acquisition and youngest children's learning and, in this regard, three aspects of the familial environment particularly favor these two processes: learning activities, the parental ability quality and the learning materials. Further, parents who have more resources (education, income) are better able to provide for their young children positive learning experiences "(Tamis-Lemonda \& Rodriguez, 2008)

The table (04) shows the results obtained for the third question.

Question 3: From which level you have integrated the French school? 
Table 5

The integration level of the French school

\begin{tabular}{|c|c|c|c|c|c|c|}
\hline \multicolumn{2}{|c|}{ Classes } & NS & PC & CE 1 & CE2 & CM 1 \\
\hline \multicolumn{2}{|c|}{ CM 1 - A } & 19 & 3 & 1 & 1 & 0 \\
\hline \multicolumn{2}{|c|}{ CM 1 - B } & 22 & 1 & 0 & 1 & 0 \\
\hline \multicolumn{2}{|c|}{ CM 1 - C } & 22 & 4 & 0 & 0 & 0 \\
\hline \multicolumn{2}{|c|}{ CM 1 - D } & 22 & 0 & 1 & 1 & 0 \\
\hline \multicolumn{2}{|c|}{ CM 1 - E } & 16 & 5 & 0 & 3 & 0 \\
\hline \multicolumn{2}{|c|}{ CM 1 - F } & 19 & 4 & 0 & 2 & 0 \\
\hline \multicolumn{2}{|c|}{ CM 1 - G } & 19 & 5 & 0 & 0 & 0 \\
\hline \multicolumn{2}{|c|}{ Total } & 139 & 22 & 2 & 8 & 0 \\
\hline \multicolumn{2}{|c|}{ Percentages } & $81.28 \%$ & $12.86 \%$ & $1.16 \%$ & $4.67 \%$ & $0 \%$ \\
\hline \multirow[b]{2}{*}{$\begin{array}{l}\text { Statistical } \\
\text { Analysis }\end{array}$} & KHI 2 & 7.563 & 8.251 & 5.186 & 6.407 & No \\
\hline & Decision & $\begin{array}{c}6 \\
\text { significative } \\
\text { to } \\
p>0.05\end{array}$ & $\begin{array}{c}6 \\
\text { significative } \\
\text { to } \\
p>0.05\end{array}$ & $\begin{array}{c}6 \\
\text { significative } \\
\text { to } \\
p>0.05\end{array}$ & $\begin{array}{c}6 \\
\text { significative } \\
\text { to } \\
p>0.05\end{array}$ & $\begin{array}{l}\text { are } \\
\text { computed } \\
\text { because } \\
\text { it is a } \\
\text { constant }\end{array}$ \\
\hline
\end{tabular}

NS : Nursery School

PC : Preparatory Course (the first year of primary school)

CE 1 : The second year ( $\left.2^{\text {nd }}\right)$ of primary school

CE 2 : The third (3rd) year of primary school

CM 1 - A : The fourth year (4th) of primary school A

CM 1 - B : The fourth year (4th) of primary school B

CM 1 - C : The fourth year (4th) of primary school C

CM 1 - D : The fourth year (4th) of primary school D

CM 1 - E : The fourth year (4th) of primary school $\mathbf{E}$

CM 1 - F : The fourth year (4th) of primary school $\mathbf{F}$

CM 1 - G : The fourth year (4th) of primary school G

The gap between registration rates at nursery school and registration rates in the other levels appears obvious. We assist therefore to early school integration in its non obligatory form; this reflects the consciousness of parents wishing to register their children in French schools abroad, the necessity of an earlier initiation of subsequent learning.

Genevieve Dannepond (1979), confirms this thesis considering the preschool as a determinant of later academic success. She recommends that those who wish to see restrict "the chances inequality " before school are supposed placing their hopes upstream in the equalizing effect that the "pre-basic" educational institution may have to "compensate " through a methodical prior preparation to the typically scholar learning, the impact of differential socialization of familial environments.

The author says that "the rapid growth of the pre-elementary education, which does not seem to be explained only by the guard function it performs but also meet the properly educational intentions of some parents, also led to examine the effects that nursery schooling may occur, particularly on the childrens subsequent education "(Dannepond, 1979, p. 33).

Dannepond (1979) strengthens these ideas by citing the example of the children who come into direct first year of elementary school (preparatory course) without pre-primary schooling. She postulates that these are less successful than those already registered at the nursery school.

The table below illustrates the results of the fourth question.

Question 4: What is the language used by your teacher during the presentation and the explanation of the situations in the PE session? 
Table 6

Language of presentation and explanation of the proposed situations in the PE session

\begin{tabular}{|c|c|c|c|c|}
\hline \multicolumn{2}{|c|}{ Classes } & $\mathbf{F r}$ & $\mathbf{F r}+\mathbf{A r b}$ & Fr + Other \\
\hline \multicolumn{2}{|c|}{ CM 1 - A } & 24 & 0 & 0 \\
\hline \multicolumn{2}{|c|}{ CM 1 - B } & 23 & 1 & 0 \\
\hline \multicolumn{2}{|c|}{ CM 1 - C } & 25 & 1 & 0 \\
\hline \multicolumn{2}{|c|}{ CM 1 - D } & 10 & 1 & 13 \\
\hline \multicolumn{2}{|c|}{ CM 1 - E } & 24 & 0 & 0 \\
\hline \multicolumn{2}{|c|}{ CM 1 - F } & 22 & 3 & 0 \\
\hline \multicolumn{2}{|c|}{ CM 1 - G } & 24 & 0 & 0 \\
\hline \multicolumn{2}{|c|}{ Total } & 152 & 6 & 13 \\
\hline \multicolumn{2}{|c|}{ Percentages } & $\mathbf{8 8 . 8 8} \%$ & $3.50 \%$ & $7.60 \%$ \\
\hline \multirow{4}{*}{$\begin{array}{c}\text { Stiatistical } \\
\text { Analysis }\end{array}$} & KHI2 & 65.769 & 8.012 & 86.176 \\
\hline & DDL & 6 & 6 & 6 \\
\hline & Decision & $\begin{array}{c}\text { Non } \\
\text { significative }\end{array}$ & $\begin{array}{l}\text { significative } \\
\text { to }\end{array}$ & $\begin{array}{c}\text { Non } \\
\text { significative }\end{array}$ \\
\hline & & to $\mathrm{p}<0.05$ & $p>0.05$ & to $\mathrm{p}<0.05$ \\
\hline
\end{tabular}

\section{Fr: French}

Fr + Arb : French and Arab

$\mathbf{F r}+$ Other : French and Other language

CM $1-\mathbf{A}$ : The fourth year (4th) of primary school A

CM 1 - B : The fourth year (4th) of primary school B

CM 1 - C : The fourth year (4th) of primary school C

CM 1 - D : The fourth year (4th) of primary school D

CM $1-\mathbf{E}$ : The fourth year (4th) of primary school $\mathbf{E}$

CM 1 - F : The fourth year (4th) of primary school $\mathbf{F}$

CM 1 - G : The fourth year (4th) of primary school $\mathbf{G}$

Thus, we can conclude that the teachers' linguistic interventions during a PE session are usually presented in the French language. We assist therefore to a predominantly monolingual speech with a school audience characterized by its ethnic diversity and, therefore, by its linguistic heterogeneity.

The results of the fifth question are presented in the table below.

Question 5: Do you find this language effective and does it help you to understand what your teacher wants to convey?

Table 7

Effectiveness of the PE teaching language

\begin{tabular}{ccc}
\hline Classes & Yes & No \\
& & 0 \\
CM 1 - A & 24 & 2 \\
CM 1 - B & 22 & 2 \\
CM 1 - C & 24 & 4 \\
CM 1 - D & 20 & 0 \\
CM 1 - E & 24 & 2 \\
CM 1 - F & 23 & 1 \\
CM 1 - G & 23 & $\mathbf{1 1}$ \\
Total & $\mathbf{1 6 0}$ & $\mathbf{6 . 4 3} \%$ \\
Percentages & $\mathbf{9 3 . 5 6} \%$ & \multicolumn{2}{c}{$\mathbf{7 . 9 9 5}$} \\
KHI 2 & \multicolumn{2}{c}{6} \\
Statistical $\quad$ DDL & significative to p > 0.05 \\
Analysis Decision
\end{tabular}

CM 1 - A : The fourth year (4th) of primary school A

CM 1 - B : The fourth year (4th) of primary school B 
CM 1 - C : The fourth year (4th) of primary school C

CM 1 - D : The fourth year (4th) of primary school D

CM $1-\mathbf{E}$ : The fourth year (4th) of primary school $\mathbf{E}$

CM 1 - F : The fourth year (4th) of primary school $\mathbf{F}$

CM 1 - G : The fourth year (4th) of primary school $\mathbf{G}$

We can admit this consensus about the effectiveness of the unilingual teaching speech, as long as we perceive the nursery school abroad, as an instance of transition from the informal familial education to the scholar formal education. The nursery school abroad allows therefore to reduce the linguistic chances inequalities between the French students and those who do not practice the French language at home. It provides an education equilibrated and adapted to the specificities of this diverse school public.

The table below illustrates the sixth question results.

Question 6: Which language do you use in your conversations with your teacher during the PE session?

Table 8

The languages used by the students during a PE session

\begin{tabular}{|c|c|c|c|c|c|}
\hline \multicolumn{2}{|c|}{ Classes } & Fr & $\mathbf{F r}+\mathbf{A r b}$ & Fr + Other & Other \\
\hline \multicolumn{2}{|c|}{ CM 1 - A } & 24 & 0 & 0 & 0 \\
\hline \multicolumn{2}{|c|}{ CM 1 - B } & 20 & 3 & 1 & 0 \\
\hline \multicolumn{2}{|c|}{ CM 1 - C } & 23 & 2 & 1 & 0 \\
\hline \multicolumn{2}{|c|}{ CM 1 - D } & 18 & 0 & 6 & 0 \\
\hline \multicolumn{2}{|c|}{ CM 1 - E } & 21 & 2 & 1 & 0 \\
\hline \multicolumn{2}{|c|}{ CM 1 - F } & 21 & 3 & 1 & 0 \\
\hline \multicolumn{2}{|c|}{ CM 1 - G } & 22 & 1 & 1 & 0 \\
\hline \multicolumn{2}{|c|}{ Total } & 149 & 11 & 11 & 0 \\
\hline \multicolumn{2}{|c|}{ Percentages } & 87.13 & $6.43 \%$ & $6.43 \%$ & $0 \%$ \\
\hline \multirow[b]{3}{*}{$\begin{array}{l}\text { Statistical } \\
\text { Analysis }\end{array}$} & KHI2 & 7.708 & 6.473 & 16.545 & No \\
\hline & DDL & 6 & 6 & 6 & $\begin{array}{c}\text { statistics } \\
\text { are }\end{array}$ \\
\hline & Decision & $\begin{array}{l}\text { significative } \\
\text { to } p>0.05\end{array}$ & $\begin{array}{c}\text { significative } \\
\text { to } \\
\mathrm{p}>0.05\end{array}$ & $\begin{array}{c}\text { Non } \\
\text { significative } \\
\text { to } \mathrm{p}<0.05\end{array}$ & $\begin{array}{c}\text { computed } \\
\text { because } \\
\text { it is a } \\
\text { constant }\end{array}$ \\
\hline
\end{tabular}

Fr : French
Fr + Arb : French and Arab
Fr + Other : French and Other language
Other : Other language
CM 1 - A : The fourth year (4th) of primary school A
CM 1 - B : The fourth year (4th) of primary school B
CM 1 - C : The fourth year (4th) of primary school C
CM 1 - D : The fourth year (4th) of primary school D
CM 1 - E : The fourth year (4th) of primary school $\mathbf{~}$
CM 1 - F : The fourth year (4th) of primary school $\mathbf{~}$
CM 1 - G : The fourth year (4th) of primary school $\mathbf{G}$

According to the sixth question results, there is a simultaneous presence of several languages giving place to an linguistic juxtaposition phenomenon during the PE session and confirming, therefore, the students linguistic heterogeneity in the while communicating with their teachers at the French school in Tunisia.

However, these results confirm also the success of the school to achieve one of its goals in the foreign contexts; we speak about "the French language mastery". In the fourth year of primary school "CM 1" and in all disciplines including EPS, the French language becomes a language of communication commonly used by students issued from different nationalities and speak several native languages. This manifestation of unification is undoubtedly the result of the anterior learnings during the previous school years in precedents.

Subsequently, we can admit that the French school in Tunisia that can be considered as a minoritarian school which" is a place of education, of acculturation, of language learning and culture transmission, of socialization and of municipalization "(Bernard, 1997, p. 509) has managed to achieve one of its tasks. We talk 
about its mission of "Frenchifying, even re-frenchifying its students and develop in them a sense of cultural identity as francophones and a sense of community belonging" (Laplante, 2001, p. 128). It has established a francophone linguistic culture among its students audience after some schooling years as shown by the results above.

We present the seventh question results in Table 8.

Question 7: Do you find this language effective and helps you to convey your reflexions to your teacher ?

Table 9

Effectiveness of the language used by the students

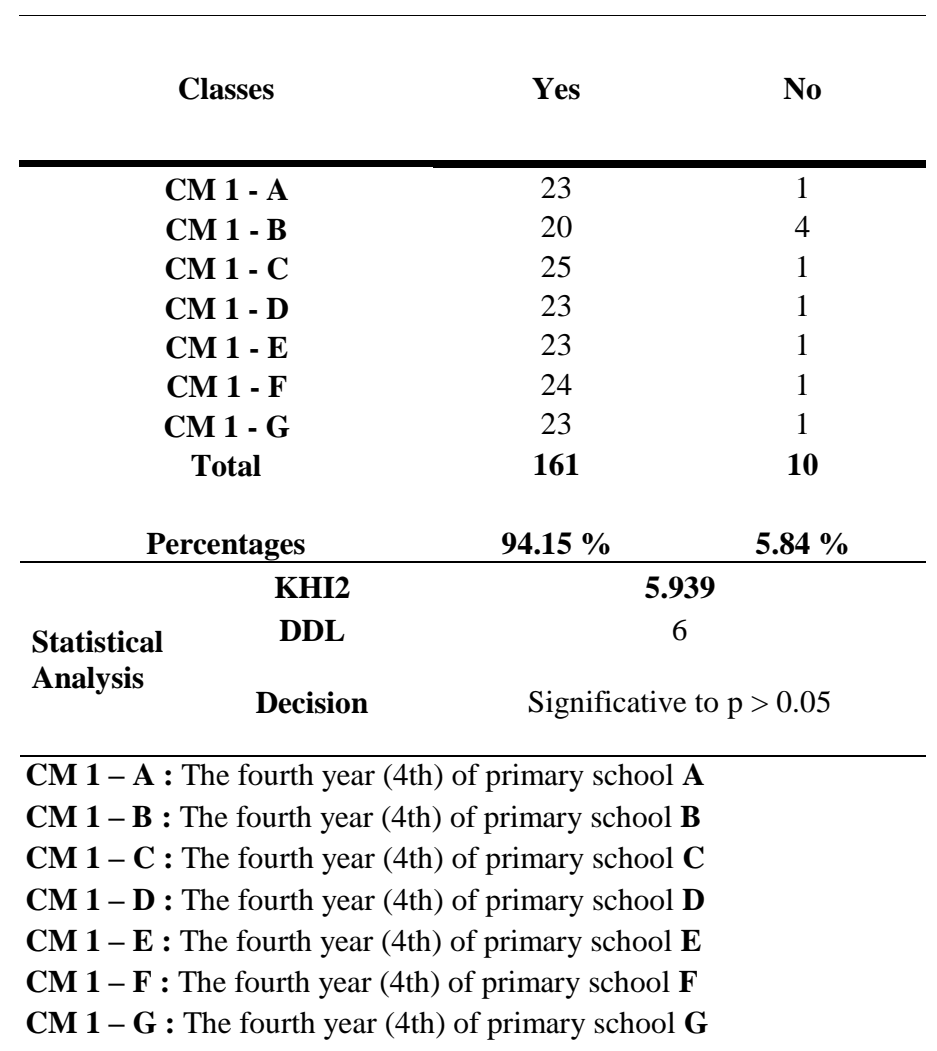

These results demonstrate the efficiency of a monolingual teaching approach with students mastering the French language, either because they come from francophone families and they practice it at home, or because they have intergred the French school since the nursery school.

Otherwise, the variables that determine the students' mastery level of the French language (understanding and communication) and its ease of use to interact with his friends or his teacher during a PE session are respectively:

- The integration of a French school since the Nursery school;

- The native language and its proximity from the French language;

- The ethnic origins (French nationality or other).

We note, however, that ethnicity cannot be a determinant of linguistic uses in the home: among 46 interviewed Tunisians students, 29 (63,04\%) are bilingual and speak the French and the Arabic at home. The parents' orientation and their intellectual level could therefore be a determinant factor of the student French language mastery.

The eighth question results are presented in table (9).

Question 8: How do you find a PE session conducted solely in French? 
Table 10

Appreciation of an PE session conducted in French

\begin{tabular}{cccc}
\hline Classes & $\begin{array}{c}\text { Easy to } \\
\text { Understand }\end{array}$ & $\begin{array}{c}\text { Difficult to } \\
\text { Understand }\end{array}$ & Other \\
\hline CM 1 - A & 18 & 2 & 4 \\
CM 1 - B & 19 & 2 & 3 \\
CM 1 - C & 23 & 0 & 3 \\
CM 1 - D & 20 & 0 & 4 \\
CM 1 - E & 20 & 2 & 2 \\
CM 1 - F & 17 & 3 & 5 \\
CM 1 - G & 23 & 0 & 1 \\
Total & $\mathbf{1 4 0}$ & $\mathbf{9}$ & $\mathbf{2 2}$
\end{tabular}

\begin{tabular}{lcccc}
\multicolumn{2}{c}{ Pourcentages } & $\mathbf{8 1 , 8 7 \%}$ & $\mathbf{5 , 2 6 \%}$ & $\mathbf{1 2 , 8 6 \%}$ \\
\hline KHI 2 & $\mathbf{8 . 1 0 5}$ & $\mathbf{7 . 7 4 8}$ & $\mathbf{3 . 8 5 7}$ \\
$\begin{array}{l}\text { Statistical } \\
\text { Analysis }\end{array}$ & DDL & $\begin{array}{c}6 \\
\text { significative } \\
\text { to } \mathrm{p}>0.05\end{array}$ & $\begin{array}{c}\text { significative } \\
\text { to } \mathrm{p}>0.05\end{array}$ & $\begin{array}{c}\text { significative } \\
\text { to } \mathrm{p}>0.05\end{array}$ \\
\hline
\end{tabular}

CM $1-\mathbf{A}$ : The fourth year (4th) of primary school $\mathbf{A}$

CM 1 - B : The fourth year (4th) of primary school B

CM 1 - C : The fourth year (4th) of primary school C

CM 1 - D : The fourth year (4th) of primary school D

CM 1 - E : The fourth year (4th) of primary school $\mathbf{E}$

CM 1 - F : The fourth year (4th) of primary school $\mathbf{F}$

CM 1 - G : The fourth year (4th) of primary school $\mathbf{G}$

These frequencies reveal that the French language, already mastered by most of the students, ensures the smooth operation of the teaching act such as it facilitates the knowledge transfer to learners not having the same cultural or linguistic profile.

The reality is, however, not confirmed by our sample totality, since (15.37\%) of the surveyed students said that a monolingual PE session is difficult to assimilate or have another opinion (eg average, normal but not easy, sometimes easy and others difficult ...). The common point resembling these class members persists in the fact that either they have not joined the French school since nursery school, or they are not French and they speak therefore another language than French at home.

This minority reflects the linguistic situation reality at French schools abroad in general and those established in Tunisia in particular. The French language as a scholar language can not be understood by all students. This conflict situation requires solutions to minimize the "chances inequality phenomenon" generally emerging in these institutions.

Especially that "in the past, the Francophone educational institution located in minority communities have the mandate, in addition to transfer knowledge and to socialize students, to ensure the reproduction of the French language and culture" (Gerin-Lajoie, 2004, p. 172).

However, the choice of French language by the fourth year of primary school students' "CM 1" reflects the success of the French school located abroad and / or minority communities to achieve one of its primary goals: facilitating the learning through the mastery of the French language.

The table 10 shows the ninth question results.

Question 9: If you are offered to choose one language to learn PE, which one of the following languages you will choose? 
Table 11

The PE teaching language preferred by the students

\begin{tabular}{|c|c|c|c|}
\hline Classes & $\mathbf{F r}$ & Arb & Other \\
\hline CM 1 - A & 21 & 1 & 2 \\
\hline CM 1 - B & 13 & 8 & 3 \\
\hline CM 1 - C & 24 & 1 & 1 \\
\hline CM 1 - D & 19 & 1 & 4 \\
\hline CM 1 - E & 17 & 6 & 1 \\
\hline CM 1 - F & 18 & 7 & 0 \\
\hline CM 1 - G & 22 & 2 & 0 \\
\hline Total & 134 & 26 & 11 \\
\hline Percentages & $78,36 \%$ & $15,20 \%$ & $6,43 \%$ \\
\hline KHI2 & 8,105 & 3,857 & 7,748 \\
\hline DDL & 6 & 6 & 6 \\
\hline $\begin{array}{l}\text { Statistical } \\
\text { Analysis }\end{array}$ & $\begin{array}{l}\text { significative } \\
\text { to } p>0,05\end{array}$ & $\begin{array}{l}\text { significative } \\
\text { to } p>0,05\end{array}$ & $\begin{array}{l}\text { significative } \\
\text { to } p>0,05\end{array}$ \\
\hline \multicolumn{4}{|c|}{$\begin{array}{l}\text { Fr : French } \\
\text { Arb : Arab } \\
\text { Other : Other language } \\
\text { CM } 1 \text { - A : The fourth year (4th) of primary school A } \\
\text { CM } 1 \text { - B : The fourth year (4th) of primary school B } \\
\text { CM } 1 \text { - C : The fourth year (4th) of primary school C } \\
\text { CM } 1 \text { - D : The fourth year (4th) of primary school D } \\
\text { CM } 1 \text { - E : The fourth year (4th) of primary school } \mathbf{E} \\
\text { CM } 1 \text { - F : The fourth year (4th) of primary school } \mathbf{~} \\
\text { CM } 1 \text { - G : The fourth year (4th) of primary school } \mathbf{G}\end{array}$} \\
\hline
\end{tabular}

What emerges from these percentages is that the fourth year of primary school students who became francophone after some schooling years in cycle 1 and cycle 2 at the French school and those who are French originals prefer a PE session conducted in French language solely. However, the percentage of students who chose another language than French ("Arabic" or "Other language") is not negligible and exceeds one fifth (1/5) of the surveyed public total. These latter claim learning PE in their native languages and this is because they do not master the French language sufficiently such as they have not integrated the French school since nursery school and they have never spoken French in extra-scholar context. This category requires therefore a special attention from teachers in particular and policy makers in general in order to optimize PE learning.

This almost collective claim of the French language by the majority of ethno-culturally heterogeneous students who are formerly registered in French school confirms the reflection of Varro (1999) who considers the French language as an "absolute condition for success".

The author fortifies his reflexion by referring to the decree of April 23, 1985 establishing the elementary school programs which postulates that "The French language mastery commands the success in elementary school. It is on the one hand a prerequisite for all the learning, on the other hand it forms a clear thinking, organized and mistress of itself, she finally promotes the success in social and professional life. That is why it is the first instrument of freedom. In the school life and in the dispensed teaching will be cultivated the virtues that underpin a civilized and democratic society: the search for truth and faith in human reason, intellectual rigor and sense of responsibility, the self-respect and the respect of the others, the spirit of solidarity and cooperation, the denial of racism, the recognition of the universal present in the different cultures, the love of France which coincides with the commitment to freedom, to equality, and to fraternity " (Varro, 2012).

\section{Conclusion}

The results of the empirical study show that the linguistic interactions of the didactic situation in PE in the French school in Tunisia are mainly monolingual in French despite the ethnic diversity and the linguistic 
heterogeneity of the school audience. This French discourse appears relatively effective such as it does not allow the transmission of the instructions to all students either because they are not basically francophone and they do not practice the French language in their familial environments, or because they have not joined the French school since the nursery school which plays, in the French schools abroad, the role of a mediator between the school learning environment and the familial learning environment.

The presence of students not mastering sufficiently the French language in a PE classroom requires, in our opinion, other things instead of technical adjustments (schematization, demonstration, groups levels ... etc). It requires a reflection and an adaptation, especially linguistics, while programming the specific teaching's contents of the French schools abroad. This adjustment is indispensable as long as "the Official programs are established for all primary schools in France. They are intended for all, but in reality, they do not seem appropriate to any of them in particular. Want to apply them uniformly everywhere is an unrealizable" (Charrier, 1918).

We assist therefore on a certain inadequacy between the French monolingual educational approach and the specificities of the linguistically heterogeneous school public in the Tunisian context. This lack of correspondence (mismatch) may therefore increase more the phenomenon of "unequal opportunities" between students already francophone and others not mastering the French language sufficiently.

\section{References}

[1]. Bali, N, (2005). Joint « theory-practice » in Tunisians physical education student teacher training. Trainers and trainees conceptions. Research and Education No. 49.

[2]. Bali, N. \& all (2006). Analysis of educational interventions in Physical and Sports Activity: discipline management in an PE session. Act of the XXIII Congress AIPU on "Innovation, Training and Research in Higher Education".

[3]. Bali, N (2013). Teachers' thought processes: the case of Tunisian University Teachers. In Creative Education volume 4, Number 7, June.

[4]. Bali, N. \& all (2013). Heterogeneity language conceptions' physical education Teachers of the Fourth (4th) Year of Primary

[5]. French Schools in Tunisia. Journal of Research \& method in Education, Vol. 1, Issue 4, p. 77-84.

[6]. Bali, N. \& all (2014). The conceptions of integration of Tunisian Physical Education cooperative teacher's and student Teacher's. Creative Education.

[7]. Bernard R. (1997). The fundamental contradictions of the minoritrian school. Journal of Science Education, XXIII (3), p. $509-526$.

[8]. Bouchez, A. (1994). White book of colleges. Report of the Committee president "A New College for All" to the attention of M.F Bayrou, Minister of National Education. Paris, MEN. 25 p. and appendices.

[9]. Chang, C.-W. (2009). Language, thought and action: Semio-construc- tivist approach in basket-ball game learning among CM2 (5 $5^{\text {th }}$ grade) pupils. Doctorate Thesis, Besançon: University of Franche-Comté.

[10]. Charrier, C.H. (1918). Lived pedagogy. Full and practical course. Paris, Nathan. p. 78.

[11]. C. (2002). The construction of knowledge in school: conditions and limits of a theoretical integration. In Brossard, M and Fijalkow, J. (2001). Learn in school Vygotskian and Piagetian perspecives. p. 17-26. Bordeaux: Bordeaux University Press.

[12]. Dannepond, G. (1979). Pedagogical practice and social classes. Comparative study of three nursery schools. Acts of the research in social sciences. Vol. 30. p. 31-45.

[13]. Dugas, E. (2004). Physical education and informal education in schools. Education and Society Review, Brussels, De Boeck. p. 2134.

[14]. Galand, B. (2009). Students' heterogeneity and learning: What role for teaching practices, Research Papers in Education and Training - No. 71 .

[15]. Gerin-Lajoie, D. (2004). The problem of identity and the French-language schools in Ontario. Francophonies of America, 18.1, p. 171-179.

[16]. Gréhaigne, J. F. et al. (2001). The teaching and learning of decision ma- king in team sports. Quest, 53, p. 59-76.

[17]. Keddie. A \& al (2012). Beyond culturalism: addressing issues of Indigenous disadvantage through schooling. Australian Educational Researcher, p. 91-108.

[18]. Laplante, B. (2001). Teach in minoritian communities: stories of teachers working in French schools. Journal of Education sciences, vol. 27, No. 1, p. 127-150.

[19]. Mahut, B. \& Gréhaigne, J.F. (2000). Communicative gestures in PE intervention. Communication displayed at the International Symposium of didactics of IUFMs Disciplines Aix-Marseille.

[20]. Mahut. B. (2003). Semiotic approach of didactic interactions: Gesture and verb in a PSE ituation. Besançon: University of Franche-Comté.

[21]. Nachon, M. (2004). Interaction on physical and sportive education: The case of Basketball. Semio-linguistics kills approach and knowledge construction. Thesis, University of Franche-comté.

[22]. Perrenoud, Ph. (2005). School facing the cultures diversity. Differentiated pedagogy between demand for equality and the right to difference. University of Geneva Faculty of Psychology and Educational Sciences.

[23]. Suchaut, B. (2007). The students' heterogeneity: a lighting by research in education. The Pedagogical Papers, No. 454, p. 18-19.

[24]. Tamis-Lemond, C.S \& Rodriguez, E.T. (2008). Role of parents to promote the learning and the acquisition of language among young children. Encyclopedia on Early Childhood Development.

[25]. Tarin, R. (2006). Learning, cultural and didactic diversity. Labor Editions, Brussels.

[26]. Varro, G. (1999). The designation of foreign students in the official texts, In: Words, No. 61, p: 49-66.

[27]. Varro, G. (2012). Official french discourse on (ex-) foreign students and their French language learning. Thenotebooksof ECCE (University of Strasbourg). 